Asia Pacific Journals

\title{
HISTORY OF CAUSE - EFFECT RELATIONSHIP BETWEEN WHOLE BODY VIBRATIONS AND MUSCULOSKELETAL DISORDERS IN TRUCK DRIVERS
}

\begin{tabular}{|c|c|c|}
\hline Ravinder Kumar & Rohit Sharma & Varinder Kumar Mittal \\
ASET, Department of Mechanical & ASET, Department of Mechanical & ASET, Department of Mechanical \\
Engineering & Engineering & Engineering \\
Amity University & Amity University & Amity University \\
NOIDA (U.P.), India & NOIDA (U.P.), India & NOIDA (U.P.), India \\
ravinderanand@ @ rediffmail.com & & \\
\hline
\end{tabular}

Abstract-Purpose - The purpose of this paper is to review the available literature related to ergonomical problems (especially musculoskeletal disorders) of truck drivers in order to trace the origin, objectives, trends and scope for future work.

Design/methodology/approach - A review of research articles was conducted for various terms, namely, ergonomic, whole body vibration and musculoskeletal disorders in truck drivers.

Findings -From the literature review, it has been observed that truck drivers faced different ergonomical problems in their daily life like pain and discomfort in different body regions and most vulnerable part of the body was lower back as most of the researchers had reported the same. The reason of this pain was the long duration of driving, sitting postures and work stressors. Keywords - Musculoskeletal disorder, back pain, whole body vibration, ergonomic, truck driver.

Keywords-component; formatting; style; styling; insert (key words)

\section{INTRODUCTION}

\section{A. Transport Ergonomics}

Ergonomics is the art and science of designing work with the workers in mind. Ergonomics means fitting work to people, not fitting people to work. A study conducted by the British Government in 1993 investigated the actual costs of injuries, including the direct costs and the indirect costs, in various industries and the researchers found that in the transportation organization a ratio of indirect to direct costs of $8: 1$ [19]. It means for every dollar of direct costs, the industry spent $\$ 8$ on indirect costs.

The field of Transport offers a variety of topics highlighting particular human-machine interactions in dynamic environments. Furthermore, technological development in this field is bringing about new users' needs resulting from changes in tasks and increasing complexity in the environment. From vehicle and in-vehicle equipment design to road environment adequacy to road users' needs and related tasks. Ergonomics and Human Factors play an important role in this field. In addition, road transport involves a great variability of road users: drivers (different ages, gender, experience, professional status, type of vehicle driven, etc.) and pedestrians. Therefore, there is a need to focus on humanmachine interactions in different situations highlighting safety, comfort and efficiency in every task performance with the aim of contributing to human-centered design.

\section{B. Importance of Truck Drivers}

Truck driving is a profession that plays an important role in to the economy of every country, yet it is a career about which people know very little. Larsen (2004) reported that surveys of the general public indicate that most people are ambivalent about truck driving and view it as a dead-end profession requiring little intelligence or skill. Nonetheless, people all over the world are dependent upon truck drivers one way or the other, and the work they perform. Manufactured goods from different parts of the country are moved to final destinations by these drivers. A truck transports nearly all goods consumed in the world. According to a study the road transport industry hauled $65 \%$ of all freight transport in India. Trucking also plays a critical role in keeping costs down. Specifically, for businesses that produce high-value, lowweight goods, inventory-carrying costs can be considerable. Many of these producers now count on trucks to deliver products efficiently so that inventory can be kept as low as possible and warehouse operating cost can be lowered.

\section{ERGONOMICAL ISSUES}

\section{A. Whole-Body vibrations}

Whole body vibration (WBV) is a generic term used where any vibration of any frequency is transferred to the human body. Whole-body vibration (WBV) is transmitted through the seat or feet of employees who drive mobile machines, or other work vehicles, over rough and uneven surfaces as a main part of their job. Large shocks and jolts may cause health risks including back-pain. The transmission of vibration to the body is dependent on body posture. The effects of vibration are complex. Exposure to WBV causes motions and forces within the human body.

Epidemiological studies of long-term exposure to WBV have shown evidence for risk to the lumbar spine and the neck and shoulder. Results of epidemiological studies also show a higher prevalence rate of low-back pain, herniated disc and early degeneration of the spine in excessive WBV- exposed workers. Exposure to WBV has also been directly related to sick leave, disability, lost work days and chronic pain.

As vibration is transmitted to the body, the effect of the vibration can be amplified by factors such as body posture, type of seating and frequency of the vibration. Individual 


\section{Asia Pacific Journals}

human body parts have their own resonant frequencies. This is why after a long drive we continue to feel as if we are still moving even after the vehicle has stopped. Vibration from engines can agitate the body to the point of causing micro fractures in the vertebrae, disc protrusion, nerve damage and acute lower back pain. Short-term exposure vibration causes only small physiological effects such as a slight degree of hyperventilation and increased heart rate. Vibration also causes increased muscle tension from voluntary and involuntary muscle contraction. Muscles become tense in order to dampen the vibration. Examples of this type of tension would be having your foot fall asleep while pressing the accelerator pedal or experiencing a tingling sensation in your hands from gripping a steering wheel too tightly. Lowfrequency vibrations of moderate intensity can induce sleep. Higher frequencies have the opposite effect. Vision can also become blurred because of the movement of the image on the retina. Vibration is also traumatic to the spine. Intervertebral discs serve as "shock absorbers" and become susceptible to injury over prolonged periods. Constant exposure to vibrations represents the ultimate cumulative trauma and prolonged exposure to whole-body vibration can lead to bulging or herniated discs.

\section{B. Work-Related Musculoskeletal Disorders}

The work-related musculoskeletal disorders are injuries or disorders of muscles, nerves, tendons, joints, cartilage, and spinal discs associated with exposure to multiple risk factors in workplace. Work related MSDs include sprains, strains, tears, back pain, soreness, pain, hurt (except the back), carpal tunnel syndrome, hernia, or musculoskeletal system or connective tissues diseases and disorders. Work related MSDs do not include disorders caused by slips, trips, falls, and motor vehicle accidents. Work-related musculoskeletal disorders are caused by work activities, for example, awkward postures, forceful and repetitive exertions.

\section{Cause-Effect Relationship Between Wbv And Msd}

The health effects of whole body vibration vary considerably in association with other factors such as ergonomic design, damping, and resonance. These factors have a great effect on the exposure characteristics and intensity levels of vibration on drivers. The main problem is caused by the vibration energy waves, almost same as noise, which are transferred from the energy source, onto the body of the driver and then transmitted through the body tissues, organs, and systems causing various effects on the structures within the body before the vibration is dampened and dissipates. The risk of illness depends on the characteristics of vibration, namely magnitude, frequency, duration, and direction. The period the drivers sits behind the wheel driving, is a reasonable time of exposure to whole body vibration. This vibration has many more widespread and varied effects; though the effects may not be felt by the individual, but they are registered and recorded by the body.

The result of a study [4] indicated that professional truck drivers were at a greater risk of developing low back pain, which is caused by various mechanisms of vibration on the musculoskeletal system of the body, namely the degeneration of the inter vertebral discs, which leads to an impairment of the mechanics of the vertebral column. This allows tissues and nerves to be strained and pinched. The nutrition of the discs is affected by long periods of sitting aggravated by vibration exposure, which causes tissue nutrients required for growth and repair of the discs to flow out by diffusion instead of inwards where they are necessary. This leads to increased wear and reduced renovation of the discs. The vertebral bodies are also injured by the vibration energy that leads to an accumulation of micro fractures at the end plates of the vertebral bodies and related pain. Muscle fatigue also occurs as the muscles try to react to the vibration energy to maintain balance and protect and support the spinal column, but these are often too slow as the muscular and nervous systems cannot react fast to the vibration shocks and loads. During active natural motion, motor control mechanisms act as a feedforward control that are continuously adjusted by supplementary feedback from sensors in muscles, tendons, and joints. Whole-body vibration causes a passive artificial motion of the human body, a condition that is essentially different from the self-induced vibration caused by locomotion.

\section{Work Stressors}

The truck driver's task is mentally demanding because of having to cope with conflicting requests. The company want the driver to keep to a tight schedule in dense traffic. The other conflicting factor is the demand to drive safely according to traffic regulations. The environment in which drivers spend the majority of their time is polluted, noisy and dangerous. It is an environment over which they have no control whatsoever and is an environment that wrecks their schedules, disrupts their home life, makes social activities and regular breaks very hard to plan and supplies constant hassle. Long weeks and extending working hours are also the factors which are responsible for occupational health of the truck drivers.

Studies have shown that there are marked health differences for truck driving compared to other occupations. Truck drivers were one of the professions with worst health, based on a range of health indicators (e.g., serum cholesterol levels, systolic blood pressure, and body weight).

\section{OBJECTIVES}

Numerous studies have identified an adverse relationship between a variety of factors such as; exposure to whole-body vibration, awkward posture, prolonged sitting, terrain condition, and musculoskeletal disorders. The objectives of this paper was to explore the literature on ergonomical problems of truck drivers in order:

- To find out the prevalence of musculoskeletal disorders among truck drivers.

- To find out the association of musculoskeletal disorders of truck drivers with the whole body vibrations.

- To determine the effect of long weeks and extending working hours on occupational health of truck drivers.

- To find out the association of work stressors among truck drivers with the prevalence of WRMSDs. 


\section{Asia Pacific Journals}

- To determine the association between prevalence and socio-demographic information and physical risk factors of musculoskeletal symptoms among truck drivers.

\section{METHODOLOGY}

A review of research articles was conducted for various terms associated with the truck drivers' viz., ergonomics, whole body vibration, musculoskeletal disorders and work stressors.

\section{LITERATURE REVIEW}

This section presents a compilation of evolution, connotation and scope of these search terms by various researchers. The intention is to compile the scholarly articles on these terms showing how ergonomical and health concerns of truck drivers have been integrated in transport industry over a period of time.

A research published in 1980 [1] entitled "An ergonomic checklist for transport and material handling machinery". In this paper, they listed the points to be assessed during systematic studies of the ergonomics of machinery in the design and testing stages and recommended values of many variables related to control positions and actuating forces, access, cab and seat dimensions and environmental issues.

High prevalence of musculoskeletal disorders (MSD) were pointed out among professional drivers. Lower back pain is very common, and has been closely related to exposure to vibration and prolonged seating. The statistics of incident rates related to MSD for the long distance trucking industry in the US confirms these findings [2].

In 1984 a report entitled "Working Environment of Tanker Truck Drivers- an Ergonomic and Ergometric Study" [3] was published in National Board of Occupational Safety and Health, Sweden. Twenty-two drivers were studied in the laboratory and during work in order to identify and measure high physical loads. Pulse recordings showed that the work is moderately strenuous. Dragging the hose from the tank truck to the filler pipe was most strenuous. This might be indicative of heavy muscular strain.

The theoretical basis and the main design and construction features of the vibration system for simulating the driver's vibration environment and limits were described in 1985 [5]. A hydraulic cylinder and pivoted frame made the concept of a pendulum vibration system a reality. The driver module was designed to simulate a heavy-vehicle drivers' environment with a typical control configuration. Depending on the driver's module position this Vibration System could produce vibration in three axes of translation and two of rotation, either singly or mixed.

It has been shown, that the blood flow restriction starts at as low as at $10 \%$ and is completely restricted at a $50 \%$ level of a muscle's maximum force capacity [6]. Restriction of blood flow gives rise to anaerobic metabolism and increases the concentration of lactic acid.

[7] reviewed vibration exposure data from surveys of truck drivers and compared the exposures with the International
Standard (1985 version) comfort criteria. Measured vibration levels ranged from $0.2 \mathrm{~m} / \mathrm{s} 2$ to $1.4 \mathrm{~m} / \mathrm{s} 2$ in the vertical direction. The author concluded that according to the International Standard comfort criteria, truck drivers suffer severe discomfort within minutes on very rough roads, within an hour or two on poor roads and within a few hours on good roads.

A study published in 1995 [8] showed that back pain is not only common, accounting for $25 \%$ of WCB cases but that it is common in a wide variety of jobs both with WBV exposure and in occupations where WBV is not present. The highest risk is for construction workers for males and for nurses' aides in females. Industrial truck and tractor operators had similar but slightly lower relative risks of back pain than carpenters or construction workers with reputed lower WBV exposure. WBV was not an outcome of interest in this study.

A large two country study (USA and Sweden) was published looking at truck drivers, bus drivers and sedentary workers [9]. The outcomes of interest were based on measuring WBV exposure, stress at work, work loss and a variety of complaints including low back, neck and shoulder pain. As expected, truck drivers had the highest exposure to WBV both daily and long term. There was a non-significant increase in the percent of truck drivers that had LBP compared to sedentary workers ( $56 \%$ v. $42 \%)$.

If the seat is not adjusted correctly, pressure points can be developed in the buttocks and back of the thighs, causing muscle strain in the lower back. If there is vibration during this period, upper back and neck muscles of truck drivers are required to hold the head in position, thereby causing continuous muscle activities, which can then lead to muscle strain. Holding the foot over the pedal continually and over an extended period, may also cause stiffness and spasms in the legs [10].

In a survey of back pain symptoms truck drivers [11], it was found that the prevalence of back pain was $50.3 \%$. Three factors related significantly to the prevalence of low back pain, these were: irregular duty time, short resting time and long driving time in a day. Eighty-one of the 153 drivers pointed out the relationship between low back pain and work, especially when vibration and road shock is involved.

Static contractions at low level over a prolonged period of time can cause muscle to atrophy, splitting, necrosis and other degeneration, which in turn precipitate as chronic muscle pain and discomfort, even when the static muscle forces are not present [12].

Prolonged sitting is associated with constant spinal pressure and hence can impede disc nutrition and consequently cause disc degeneration [13]. Research has also shown that lumbar disc herniation may result from prolonged sitting in the typical flexed posture. This is especially the case if sitting occurs in motor vehicles where the vibration forces add to the stress on the discs, as it does in commercial heavy equipment driving. Long driving hours, according to the National Transportation Safety Board, include time on the wheel in excess of 10 hours, combined with limited and insufficient rest hours. Driver fatigue is an important safety issue facing the road transport 


\section{Asia Pacific Journals}

industry, and the most dangerous aspect of driver fatigue is tiredness and falling asleep at the wheel [14].

In a study conducted on drivers, the most of the respondents $(81 \%)$ reported some musculoskeletal pain during the previous 12 months and $60 \%$ reported low back pain. Contrary to expectations, vibration exposures were significantly lower among those who suffered musculoskeletal symptoms when distance was used as an exposure measure. Manual handling and subjective ratings of seat discomfort were associated with reported musculoskeletal problems [15].

In a study [16] video and BSM comparisons showed that drivers were accurate at self-monitoring frequent environmental conditions, but less accurate at monitoring trunk postures and rare work events. The current study identified four predictors of severe trunk postures that can be modified to reduce risk of injury among truck drivers and showed that workers can produce reliable self-assessment data with BSM methods for frequent and easily discriminated events environmental.

The overall prevalence of the back pain in the truck drivers was found to be $74 \%$ in India [17].

A study [18] indicates that muscle fatigue and pain can develop at much lower muscle contraction levels. This model indicates that even at less than 5 percent of muscle maximum capacity, muscle fatigue and pain can develop if the tension is sustained for a prolonged period of time (between 1000 and 10000 seconds).

A study was conducted on bus and truck drivers in USA and it was found that increased level of low back pain was a significant predictor of increased fatigue when adjusted for age, gender, BMI, job satisfaction, years and miles driven [20].

Another research concluded that professional bus and truck drivers suffer from pain syndromes of particular body parts and their occurrence is related to the kind of the work performed [21].

In a study on bus and truck drivers, it was established that the cumulative incidence of 12-month low back outcomes was $16.8 \%$ for LBP, $9.3 \%$ for chronic LBP, and $21.8 \%$ for sciatic pain [22].

The findings of a study on truck drivers in India showed that $78.6 \%$ of truck drivers had musculoskeletal disorders in one year [23].

In a study on truck drivers it was concluded that self-reported cervical herniated disc, nuchal pain, arm/forearm weakness, arm/forearm numbness, and finger numbness were significantly more prevalent as the driver's duration of exposure increased [24].

The findings of a study [25] on truck drivers in USA demonstrated that there were substantial differences in health risk prediction between the predominant axis exposure (advocated by the European Union Vibration Directives) and vector sum exposures.

\section{OBSERVATIONS, ANALYSIS, AND DISCUSSION}

The findings of this literature review study show that there is a clear correlation between musculoskeletal disorders (back pain, neck pain, shoulder pain, knee pain, ankle pain, wrist pain, elbow pain, hip/thigh pain, fatigue etc.), work stressors (tension-anxiety, depression dejection, anger-hostility, confusion, number of daily and weekly working hours, psychosocial work factors etc.), and whole body vibration exposure. Results of the studies conducted by different researchers showed a high prevalence of pain among drivers in different body regions but back and neck were the most vulnerable part of body. Back pain in some cases was as high as $96 \%$. This is because of vibration affecting tendon or muscle structure and/or pain receptors. The main factor responsible for this pain was the $\mathrm{WBV}$ as during the long hours of driving vibrations produced through vehicle transfer to the different parts of the body but the maximum vibrations transfer to the back and neck. So, the vehicles which produce high vibrations such as buses, trucks, earth moving machines, tractors etc. resulted in high prevalence of pain in different body regions.

The parts of the body most likely to be injured during exposure to whole-body vibration depend on the magnitude of vibration, distribution of the motion within the body, body postures, and the frequency of vibration, direction and duration.

But several confounding factors make it difficult to determine the exact relationship between MSDs and whole-body vibrations. Some of these factors are age, sitting for long periods, posture, climatically poor working conditions, workloads and work stress.

\section{CONCLUSION AND FUture SCOPE OF RESEARCH}

This is concluded from the literature review that most of the studies are conducted in foreign countries. In comparison, a few studies are conducted in India. And most of the studies are based on the questionnaires. So, the results obtained from these studies can be conflicting. As heavy vehicle drivers are severely exposed to high intensity vibrations, therefore, to understand the effect of WBV especially in terms of MSDs among Indian drivers an intense study is needed by considering more field measurement and also medical examinations. So, a study can be conducted by taking the different factors into consideration such as:

1) Individual factors like age, height, weight etc.

2) Anthropometric data recording.

3) The exposure information including questions regarding postural stress, duration of WBV, mental stress and perception of muscular tension.

4) Physiological demand such as heart rate variability and $\mathrm{VO}_{2}$ max.

5) Biomechanical analysis.

6) Role of different work stressors in generating MSDs.

7) Electromyography study to know the effect of vibration on muscles.

By examining these factors more reliable results can be obtained as these factors are more responsible for the generation of MSDs. 


\section{Asia Pacific Journals}

\section{References}

[1] J.E. Hansson and B. Pettersson, "An ergonomic checklist for transport and material handling machinery," National Board of Occupational Safety and Health, Skog sarbeten, 1980.

[2] A.L. Backman, "Health surveys of professional drivers," Scandinavian Journal of the Work Environment and Health," vol. 9, pp. 30-35, 1983.

[3] Hedberg, et al (1984) "Working Environment of Tanker Truck Driversan Ergonomic and Ergometric Study," National Board of Occupational Safety and Health, Sweden.

[4] M. Bovenzi, A. Zadini, "Self-reported low back symptoms in urban bus drivers exposed to whole-body vibration," Spine, vol. 17, pp. 10481059, 1992.

[5] A. Purdy, D. Simic, W. Conner and D. Dunn, "Development of a Vibration System for the Study of Whole-Body Vibration Effects on Drivers," SAE Technical Paper 851513, doi:10.4271/851513, 1985.

[6] G. Sjogaard, B. Kiens, K. Jorgensen, and B. Saltin, "Intramuscular pressure, EMG and blood flow during low level prolonged static contraction in man," Acta physio. Scand, vol. 128, pp. 475-484, 1986.

[7] J. M. Randall, "Human subjective response to lorry vibration: implications for farm animal transport,” J. Agric. Engg. Res, Vol. 52, pp. 295-307, 1992.

[8] H. Guo, S. Tanaka, L.L. Cameron and P.J. Seligman, "Back pain among workers in the United States: national estimates and workers at high risk," Am J Ind Med, vol. 28, pp. 591-602, 1995

[9] M.L. Magnusson, "Are occupational drivers at an increased risk for developing musculoskeletal disorders?," Spine, vol. 21(6), pp. 710-717, 1996.

[10] S. Konz, and S. Johnson, "Work design: Industrial Ergonomics," 4th Edition Holcomb Hathaway, Publishers Inc, Scottsdale, 1998.

[11] M. Masabumi, S. Yasumasa, N. Yoshihito, G. Yoshikazu, and K Kazuhiro, "An epidemiological study of occupational low back pain in truck drivers," J Nippon Med Sch, vol. 67 (3), pp. 186-190, 2000.

[12] National Research Council and Institute of Medicine, "Musculoskeletal Disorders and the Workplace: Low Back and Upper Extremities. Panel on Musculoskeletal Disorders and Workplace," Commission on Behavioral and Social Sciences and Education. Washington, DC: National Academy press, pp. 199-207, 2001.

[13] P.C. Adam, W. S. Alan and R.E. TAMMY, "Predictors of whole-body vibration exposure experienced by highway transport truck operators," Ergonomics, vol. 47, no. 13, pp. 1432-1453, 2004.

[14] R. De Castro, J. Gallo and J. Loureiro, "Tiredness and Sleepiness in Bus Drivers and Road Accidents in Peru: A Quantitative Study," Pan American Journal of Public Health, vol. 16 (1), pp. 11-18, 2004.

[15] M. J. M. Robb and N. J. Mansfield, "Self-reported musculoskeletal problems amongst professional truck drivers," Ergonomics, Vol. 50, No. 6, pp. 814-827, 2007.

[16] R. Olsona, D.I. Hahnb and A. Buckert, "Predictors of severe trunk postures among short-haul truck drivers during non-driving tasks: An exploratory investigation involving video-assessment and driver behavioural self-monitoring," Ergonomics, Vol. 52, No. 6, pp. 707-722, 2009.

[17] M. Goon, S. Ghoshal, B. Chandrasekaran and B. C. Sharma, "Prevalence of Low Back Pain in Long Distance Truck Drivers of Mountainous Terrain," Advances in Occupational, Social and Organizational Ergonomics, 2010

[18] D.B. Chaffin, G.B.J. Andersson and B.J. Martin, Occupational Biomechanics, Fourth Edition, Wiley-Interscience publisher, page 25 27, 2006.

[19] I. Rodriguez, "Introduction to Transportation Ergonomics," Infrastructure, Health and Safety Association, 2011.

[20] A. Christensen, F. Petersen, S. Soret and R. S. Hwang, "The Association between Low Back Pain and Fatigue among Commercial Drivers," Occupational Medicine \& Health Affairs, Vol. 1 Issue 1, 2013.

[21] E. Zielinski, J. Telak and M. P. Pain "Disorders among Professional Drivers in the Aspect of the Conducted Research and Rehabilitation," Journal of Kones Powertrain and Transport, Vol. 21, No. 4, 2014.

[22] M. Bovenzi, "Metrics of Whole-Body Vibration and ExposureResponse Relationship for Low Back Pain in Professional Drivers: A Prospective Cohort Study," International Archives of Occupational and Environmental Health, 2008
[23] A. Mozafari, M. Vahedian, S. Mohebi, and M. Najafi, "Work-Related Musculoskeletal Disorders in Truck Drivers and Official Workers," Acta Medica Iranica, vol. 53, No. 7, 2015

[24] F.Y. Lan, Y.W. Liou, K.Y. Huang, H.R. Guo and J.D. Wang, "An investigation of a cluster of cervical herniated discs among container truck drivers with occupational exposure to whole-body vibration," Advance Publication Journal of Occupational Health, 2015.

[25] J.H. Kim, L. Aulck, D. Trippany and P.W. Johnson, "The effects of work surface hardness on mechanical stress, muscle activity and wrist postures," Work, vol. 52, pp. 231-244, 2015. 